\title{
The effect of subclinical mastitis on milk yield in dairy goats
}

\author{
G. Koop,${ }^{\star 1}$ T. van Werven, ${ }^{*}$ H. J. Schuiling, $†$ and M. Nielen ${ }^{\star}$ \\ *Department of Farm Animal Health, Faculty of Veterinary Medicine, Utrecht University, Utrecht, $3584 \mathrm{CL}$, the Netherlands \\ tWageningen UR, Livestock Research, Lelystad, $8219 \mathrm{PH}$, the Netherlands
}

\begin{abstract}
The aims of this study were to estimate milk yield (MY) losses associated with subclinical intramammary infection (IMI) in dairy goats and to assess if somatic cell count (SCC) can be used to estimate such MY losses. We used 2 data sets to study these questions. The first data set consisted of 5 herds. Milk production and SCC were recorded during 1 lactation. From approximately 100 does in each herd, milk samples were collected on 3 occasions during lactation for bacteriological culture. Linear mixed regression was used to estimate the effect of IMI on MY. The second data set consisted of 6 large herds, in which some of the goats had an extended lactation $(\geq 2 \mathrm{yr})$. Milk yield and SCC data were recorded without bacteriological culture. The data showed that bacterial infection was related to an increase in SCC. Infections with major pathogens were rare and associated with a decreased MY; infection with coagulase-negative staphylococci did not affect MY, whereas infection with Corynebacterium bovis was associated with increased MY. A negative correlation was observed between SCC and MY, but the data suggested that this negative correlation was attenuated rather than caused by IMI. Furthermore, SCC seemed to be affected by MY via a dilution effect. Hypotheses about biological mechanisms behind these observations are discussed. This paper shows that MY losses caused by subclinical udder infections are limited in goats, and that SCC cannot be used to estimate the magnitude of these losses.
\end{abstract}

Key words: goat, milk yield, somatic cell count, subclinical mastitis

\section{INTRODUCTION}

One of the cost factors of subclinical mastitis is milk production loss. In dairy goats, milk is relatively expensive compared with that of cattle, and no quota system exists. Therefore, it is important to study to what extent milk yield (MY) is reduced by subclinical

Received June 17, 2010.

Accepted September 10, 2010.

${ }^{1}$ Corresponding author: g.koop@uu.nl mastitis. Two definitions of subclinical mastitis are used in the literature. Some authors used SCC as an indicator of IMI, whereas others used positive bacteriological culture in the absence of clinical symptoms.

In cattle, SCC commonly is used as an estimator of MY loss due to subclinical IMI (Halasa et al., 2007). A general trend of a milk loss of $0.5 \mathrm{~kg} / \mathrm{d}$ per 2 -fold increase of SCC $>50,000$ cells $/ \mathrm{mL}$ is used (Hortet and Seegers, 1998). It is, however, unclear if SCC in goats can be used in a comparable way. Studies on the relationship between SCC and MY in goats have consistently reported a negative correlation (Zeng and Escobar, 1995; Zeng et al., 1997; Moroni et al., 2005a). Baudry et al. (1997) categorized goats according to their SCC level and concluded that goats in a higher SCC class had a lower MY, representing milk losses of 7 to $17 \%$. Intramammary infection, however, is not the only factor that affects SCC and MY. The observed correlation between MY and SCC may have been confounded with stage of lactation (Haenlein, 2002). Rota et al. (1993) showed that SCC follows an inverse-lactation curve, so that low cell counts coincide with high MY and vice versa. It is therefore unclear if the observed negative correlation reflects the effect of disease on production, or if it is also the result of a dilution effect of MY on the concentration of somatic cells (de los Campos et al., 2006). Therefore, the negative correlation between SCC and MY may be an overestimation of the detrimental effect that can be attributed to true IMI.

Bacteriological culture of milk samples has been used in other studies to determine the effect of IMI on MY, but yielded inconclusive results. Positive bacteriological culture was associated with a decrease in milk production [ranging from 0.26 (Leitner et al., 2004a) to $0.58 \mathrm{~kg} / \mathrm{d}$ (Merin et al., 2004), up to as much as 0.8 $\mathrm{kg} / \mathrm{d}$ (Dulin et al., 1983)], but other authors reported no significant difference in MY between infected and noninfected animals (Sánchez et al., 2002; Moroni et al., 2005a,c; Min et al., 2007). Two studies compared the MY between the infected and uninfected half of the same udder, and reported significantly lower yield in the affected half (Caruolo, 1974; Leitner et al., 2004b).

Precise and pathogen-specific estimates of the MY loss associated with subclinical IMI are needed. Fur- 
thermore, the negative correlation between SCC and MY needs to be elucidated to assess the usability of SCC for estimation of production losses due to IMI. The goals of this study were (1) to estimate the effect of infection with specific pathogens on MY and (2) to study the relationship between SCC and MY in detail, to answer the question of whether SCC can be used in goats to estimate of MY losses.

\section{MATERIALS AND METHODS}

\section{Study Design}

The study comprised 2 parts: part 1 related bacteriological culture results to MY, and part 2 explored the relationship between SCC and milk yield and determined the effect of lactation stage and pregnancy. Both parts were based on longitudinal prospective field studies in Dutch dairy goats.

\section{Data Collection}

Part 1. By mail, 273 Dutch goat farmers (about $80 \%$ of all professional Dutch dairy goat herds) were invited to participate in this study on subclinical mastitis. From the 24 responding farms, we selected 5 commercial dairy goat farms for this study. Criteria for inclusion were willingness of the farmer to participate, accuracy of animal identification and registration, and the expected dates of kidding. On 4 farms, we selected 100 goats and on 1 farm, we selected 130. Approximately $30 \%$ of these were yearling does and approximately $30 \%$ were about to start a second lactation; the rest were older animals. Farmers were asked to record all cases of clinical mastitis. Every 6 wk, MY was recorded and composite milk samples were collected at morning and evening milking for SCC measurement. Somatic cell count was measured with a Fossomatic 5000 (Foss, Hillerød, Denmark), which was calibrated with cows' milk, which is the standard calibration method (Koop et al., 2009). Milk samples for bacteriological culture were taken 3 times during lactation, always within 2 $\mathrm{d}$ after a MY recording. The first sampling took place between $\mathrm{d} 4$ and 42 in lactation; the second was $6 \mathrm{wk}$ later. The third sampling was taken within 2 mo after introduction of the breeding bucks. This occasion was not the same for all herds and varied between 24 and 36 wk after the first sample. Kidding dates were recorded to assess whether an animal had been pregnant during the study period. Because of control measures taken in a recent human outbreak of Q-fever in the Netherlands (Van den Brom and Vellema, 2009), almost all pregnant animals on 3 of the 5 farms were culled shortly before kidding, so the actual kidding date could not be record- ed. The expected kidding date for these animals was therefore estimated by the farmers based on the time of introduction of the breeding buck. The conception date was calculated by subtracting the average pregnancy duration for goats, $150 \mathrm{~d}$ (Smith and Sherman, 2009), from the date of kidding.

Duplicate foremilk samples were collected from both udder halves for bacteriological culture. After discarding 3 squirts of milk, the teat end was disinfected with cotton and alcohol. About $8 \mathrm{~mL}$ milk was collected in a sterile plastic vial. Disinfection was repeated and a second sample was taken. This process was repeated for the other udder half. The milk samples were cooled with ice packs and immediately transported to the Melkcontrolecentrum (MCC) Flanders laboratory (Lier, Belgium) for bacteriological culture, according to National Mastitis Council guidelines.

An udder half was considered infected if at least 1 cfu of the same pathogen was cultured from $0.01 \mathrm{~mL}$ of milk from both samples. Milk samples were considered contaminated when 3 or more different types of bacteria were cultured. If 1 of the 2 samples was contaminated or showed no growth, the udder half was analyzed as culture negative. When both samples were contaminated, the half was excluded from the analyses. When both duplicate samples yielded the same 2 pathogens, it was considered to be a mixed IMI. Mixed infections with CNS and Corynebacterium bovis were analyzed as a separate group. A mixed infection with Staphylococcus aureus and C. bovis was analyzed as Staph. aureus; Streptococcus dysgalactiae and CNS were analyzed as Strep. dysgalactiae; Bacillus spp. and C. bovis were analyzed as C. bovis. Major pathogens (Staph. aureus, Strep. dysgalactiae, Arcanobacterium pyogenes, gram-negative pathogens, and esculin-positive cocci) were analyzed together as one group. Because MY was recorded at goat level, IMI status was also categorized at goat level. An animal was considered infected if one or both halves were positive for a certain pathogen. If an animal was infected with both a major and a minor pathogen, it was analyzed as infected with a major pathogen. If both minor pathogens (CNS and C. bovis) were present in 2 halves of the same animal or as a mixed infection in 1 half, the animal was classified as CNS and C. bovis infected.

A subset of the data was used to study the relationship between SCC and MY in culture-negative animals. For this subset, culture negative was defined as no growth in any of the 2 duplicates from both halves, and only animals that were culture negative on each of the 3 sampling occasions were included.

Part 2. We used data from 6 herds that were selected for a study on extended lactations (Schuiling, 2007). Herds were selected on willingness of the farmers 
to participate. Farmers had to use extended lactations, perform milk production recording of all individual animals, and use a management program for data recording. In this study, the herds were followed for $2 \mathrm{yr}$. The total number of milking goats in this study was 4,493 and approximately $30 \%$ of the goats had an extended lactation covering $2 \mathrm{yr}$ or more, without kidding in the meantime. For the present study, extended lactations were truncated at $60 \mathrm{wk}$ in milk; the remaining records were discarded. Many animals had an extended lactation, making it possible to separate the effect of pregnancy on MY from the effect of lactation stage. Milk production and SCC were recorded every $6 \mathrm{wk}$. Kidding date and parity were recorded by the farmers. The day of conception was determined as described above. Records were included in the data set only if certainty on pregnancy status existed. If no final kidding date was recorded, then only records before $150 \mathrm{~d}$ before the last recorded date were included.

\section{Data Analysis}

Daily milk production was calculated as the sum of the morning and evening milking, and SCC was calculated as the mean of the morning and evening milking. The SCC was categorized in a variable with 4 classes (denoted as SCC class): $<500,500$ to $999,1,000$ to 1,999 , and $\geq 2,000 \times 10^{3}$ cells $/ \mathrm{mL}$. Somatic cell count was also used as a continuous $\log _{10}$-transformed variable $(\log \mathrm{SCC})$.

Part 1. All records from animals that had a clinical mastitis episode during the study period were excluded from the analyses. Probability of infection at goat level with major pathogens, CNS, C. bovis, and with both CNS and C. bovis in each of the SCC classes was calculated by dividing the number of goats with 1 or 2 infected glands in an SCC class by the total number of goats in that class.

The effect of infection on milk production was assessed with 2 linear mixed regression models, with MY as the dependent variable. For model 1, we used the 3 bacteriological culture measurements and the corresponding MY recordings; the model was specified as follows:

$$
\begin{aligned}
\mathrm{MY}_{\mathrm{ijk}} & =\mu+\mathrm{INF}_{\mathrm{ijk}}+\mathrm{PAR}_{\mathrm{jk}}+\mathrm{PREG}_{\mathrm{ijk}} \\
& +\mathrm{WIM}_{\mathrm{ijk}}+\gamma_{\mathrm{jk}}+\delta_{\mathrm{k}}+\mathrm{e}_{\mathrm{ijk}}
\end{aligned}
$$

where i corresponds to the ith sampling occasion; j corresponds to the jth goat; $\mathrm{k}$ corresponds to the kth herd; $\mu$ represents the intercept; INF represents infection status at sampling occasion i as a categorical variable with 5 classes (culture negative, C. bovis infected,
CNS infected, mixed infection with $C$. bovis and CNS, and infection with major pathogens); PAR represents parity as a categorical variable with 4 classes (first, second, third, or fourth and higher); PREG represents pregnancy at sampling occasion i, modeled as a 6-class variable (nonpregnant, 1, 2, 3, 4, or 5 mo pregnant); WIM represents lactation stage at sampling occasion i as a categorical variable with weekly levels to model the lactation curve; $\gamma_{\mathrm{jk}}$ represents the repeated variation for the jth goat in the kth herd; $\delta_{\mathrm{k}}$ is random variation in the kth herd; and $\mathrm{e}_{\mathrm{ijk}}$ represents residual error. For model 2, we used the culture results of only the first sampling, and regressed that on the 6 weekly milk production recordings until $42 \mathrm{wk}$ in lactation:

$$
\begin{aligned}
& \mathrm{MY}_{\mathrm{ijk}}=\mu+\text { INF_FIRST } \mathrm{jk}_{\mathrm{j}}+\mathrm{PAR}_{\mathrm{jk}}+\mathrm{PREG}_{\mathrm{ijk}} \\
& +\mathrm{WIM}_{\mathrm{ijk}}+\gamma_{\mathrm{jk}}+\delta_{\mathrm{k}}+\mathrm{e}_{\mathrm{ijk}},
\end{aligned}
$$

where i denotes the ith milk production recording; INF_FIRST represents the infection status on the first sampling occasion as a 5-class variable (culture negative, C. bovis infected, CNS infected, mixed infection with $C$. bovis and CNS, and infection with major pathogens); the other variables are as defined above. Random intercepts and random slopes were allowed if significant $(P<0.05)$ based on the likelihood-ratio test. First-order autoregressive and compound symmetry covariance structures were considered, and the covariance structure with the lowest Akaike's information criteria was included if it yielded a significant $(P<0.05)$ improvement of the model. The fit of the model and the assumptions of homoscedasticity and normality were checked by visual inspection of the plots of standardized residuals against predicted values and histograms and quantile-quantile plots of standardized residuals. Weighted variance structures were modeled if necessary based on these plots, and the significance of the improvement of the model was assessed with likelihoodratio tests.

In the subset of $3 \times$-culture-negative animals, we regressed SCC class on MY and corrected for parity, pregnancy, and weeks in milk. A random goat effect was included, but herd was included as a fixed factor because convergence could not be attained if it were modeled as a random effect. A comparable model was fitted for the full data set to explore the difference in relationship between SCC and MY in infected and uninfected animals. Both models can be written as follows:

$$
\begin{aligned}
\mathrm{MY}_{\mathrm{ijk}}= & \mu+\mathrm{SCC}_{-} \mathrm{CLASS}_{\mathrm{ijk}}+\mathrm{PAR}_{\mathrm{jk}}+\mathrm{PREG}_{\mathrm{ijk}} \\
& +\mathrm{WIM}_{\mathrm{ijk}}+\operatorname{HERD}_{\mathrm{k}}+\gamma_{\mathrm{jk}}+\mathrm{e}_{\mathrm{ijk}},
\end{aligned}
$$


where i denotes the ith milk production recording; SCC_CLASS represents the SCC level at sampling occasion i categorized in 4 classes as outlined previously; HERD represents a fixed effect of herd; and the other variables are defined as given above. The model building strategy was as described for Models 1 and 2 .

Part 2. We analyzed the relationship between logSCC and MY and estimated the effects of parity, pregnancy, and lactation stage on this relationship by adding these variables 1 by 1 to a linear mixed-regression model with random intercepts for lactation within goat, within herd. The full model was specified as follows:

$$
\begin{aligned}
& \mathrm{MY}_{\mathrm{ijkl}}=\mu+\operatorname{logSCC} \mathrm{Sikl}_{1}+\mathrm{PAR}_{\mathrm{jkl}}+\mathrm{PREG}_{\mathrm{ijkl}} \\
& +\mathrm{WIM}_{\mathrm{ijkl}}+\operatorname{HERD}_{\mathrm{k}}+\lambda_{\mathrm{ijkl}}+\gamma_{\mathrm{jkl}}+\delta_{\mathrm{k}}+\mathrm{e}_{\mathrm{ijkl}}
\end{aligned}
$$

where 1 denotes the lth lactation of the jth animal; logSCC represents the $\log _{10}$ transformed SCC at sampling occasion $i ; \lambda$ represents the repeated variation within the lth lactation of the jth animal in the kth herd; and the other variables as defined previously. Modeling was done as described above. In a subset of the data, containing only the animals with a first MY recording between 5 and $35 \mathrm{~d}$ in milk, the relationship between SCC class at first measurement and MY and logSCC in the remaining lactation up to 10 mo in lactation was explored.

All models were built in $\mathrm{R}$ (version 2.11.0, R Foundation for Statistical Computing, Vienna, Austria; http:// www.r-project.org/), using the LME function from the NLME library (Pinheiro et al., 2009).

\section{RESULTS AND DISCUSSION}

\section{IMI and SCC}

On the first sampling occasion in early lactation, about $48 \%$ of the goats were infected in one or both udder halves. This figure was approximately the same on the second sampling occasion, but it increased to $58 \%$ in the late lactation sampling, in agreement with Moroni et al. (2005b). The prevalences of various pathogens and associated mean SCC are reported in Table 1. The overall prevalence of infection was higher in this study compared with the literature. In a review by Contreras et al. (2003), goat level prevalences ranged from 19.4 to $47 \%$, but most articles reported prevalences of around $30 \%$. The high prevalence in our study, however, was caused by a high prevalence of $C$. bovis; the prevalence of the other species was in line with previous research. Corynebacterium bovis was almost exclusively found on 2 of the 5 farms, but in very high numbers. Sánchez et al. (1999) reported an animal-level prevalence of corynebacteria of $8 \%$. Other authors reported even lower prevalences for this pathogen (Contreras et al., 1995, 2003). A higher prevalence of $C$. bovis occasionally has been described in cattle, and frequency of isolation usually is reduced significantly in herds using a teat dip and dry cow therapy (Counter, 1981; Kolkman et al., 2006). In Dutch goat dairies, however, teat dipping and dry goat therapy are almost never applied, as was the case for the herds in this study. Coagulase-negative staphylococci were cultured from 1 or both udder halves in $18 \%$ of the goats, corresponding to what has been reported in the literature (East et al., 1987; Contreras et al., 1995; Sánchez et al., 1999). The prevalence of infection increased with SCC class (Table 2). Major pathogens were rare and were mostly observed in the highest SCC class $(>2,000,000$ cells $/ \mathrm{mL})$. Less than $20 \%$ of the animals in this SCC class were infected with a major pathogen. The farmers reported in total 9 cases of clinical mastitis. All records from these animals were excluded from the analyses because the majority of clinical mastitis cases occurred early in lactation, and we wanted to eliminate any effects of clinical mastitis on MY (Gröhn et al., 2004).

\section{IMI and MY}

Major Pathogens. The association between infection status and MY is shown in Table 3. It shows that infection with major pathogens was associated with a production loss of $0.13 \mathrm{~kg} / \mathrm{d}$, but this was not statistically significant. When infection status of the first month of lactation was used as predictor for the production in the remainder of the lactation, the estimated MY loss was higher $(0.29 \mathrm{~kg} / \mathrm{d})$, indicating that major infections may have a long-term effect on milk production. The majority of major infections in this study were caused by Staph. aureus. Moroni et al. (2005c) found that chronic infection with Staph. aureus was associated with a loss of $0.14 \mathrm{~kg} / \mathrm{d}$, but this also was not statistically significant. A decline in MY due to subclinical infection by major pathogens would be expected because of the high pathogenicity of this agent (Contreras et al., 2003). In cattle, subclinical infections with major pathogens are associated with significant MY decrease (Reksen et al., 2007; Schukken et al., 2009). In our study, the estimated effect of major infections on MY was small, but due to the variability of MY and a low prevalence of major infections, the estimate was not very precise. Based on the $95 \%$ CI, it seems improbable that the true population mean of the effect is larger than $0.75 \mathrm{~kg} / \mathrm{d}$. Together with the low prevalence of subclinical major infections, the total milk loss associated with these infections in an average herd is probably limited. In our study, records from 
Table 1. Prevalence and composite SCC of goats infected with Corynebacterium bovis, CNS, a mixed infection of $C$. bovis and CNS, or major pathogens cultured from goats in 5 Dutch dairy herds, sampled twice in early lactation and once in late lactation

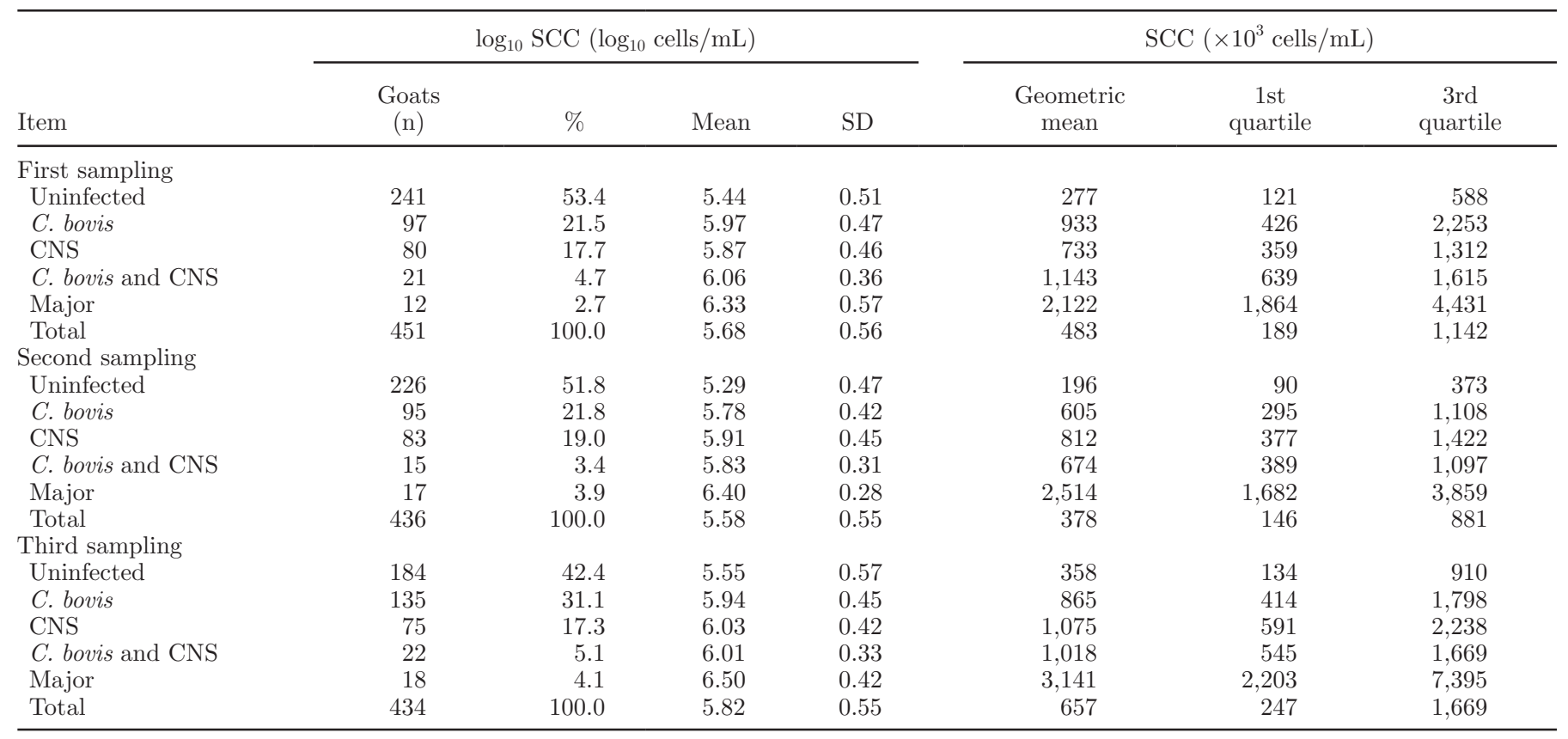

goats that had a case of clinical mastitis were removed from the data set. Inclusion of these records yielded a slightly stronger effect of major pathogens on MY than removing them. In model $1, \beta$ for major pathogens was -0.22 (95\% CI: -0.56 to 0.12 ), and in model $2, \beta$ was -0.32 ( -0.75 to 0.11$)$; no effect on the other estimates was seen.

CNS. Infection with CNS was not related significantly to MY (Table 3), as was also described by Moroni et al. (2005a). Leitner et al. (2004b) and Merin et al. (2004), however, did observe a significant difference in MY between CNS-infected and -uninfected udder halves of the same goat. Possibly, a decrease in MY in 1 half can be compensated in the other half. This is in line with a study that shows that infection with CNS in both halves is associated with a MY loss, but infection in 1 half is not (Leitner et al., 2004a).

C. bovis. Infection with $C$. bovis was associated with a higher MY (Table 3), which has not, to our knowledge, been described in goats or in cattle. A positive

Table 2. Prevalence of infection with CNS, Corynebacterium bovis, a mixed infection of $C$. bovis and CNS, or major pathogens for different classes of composite SCC in goats in 5 Dutch dairy herds, sampled twice in early lactation and once in late lactation

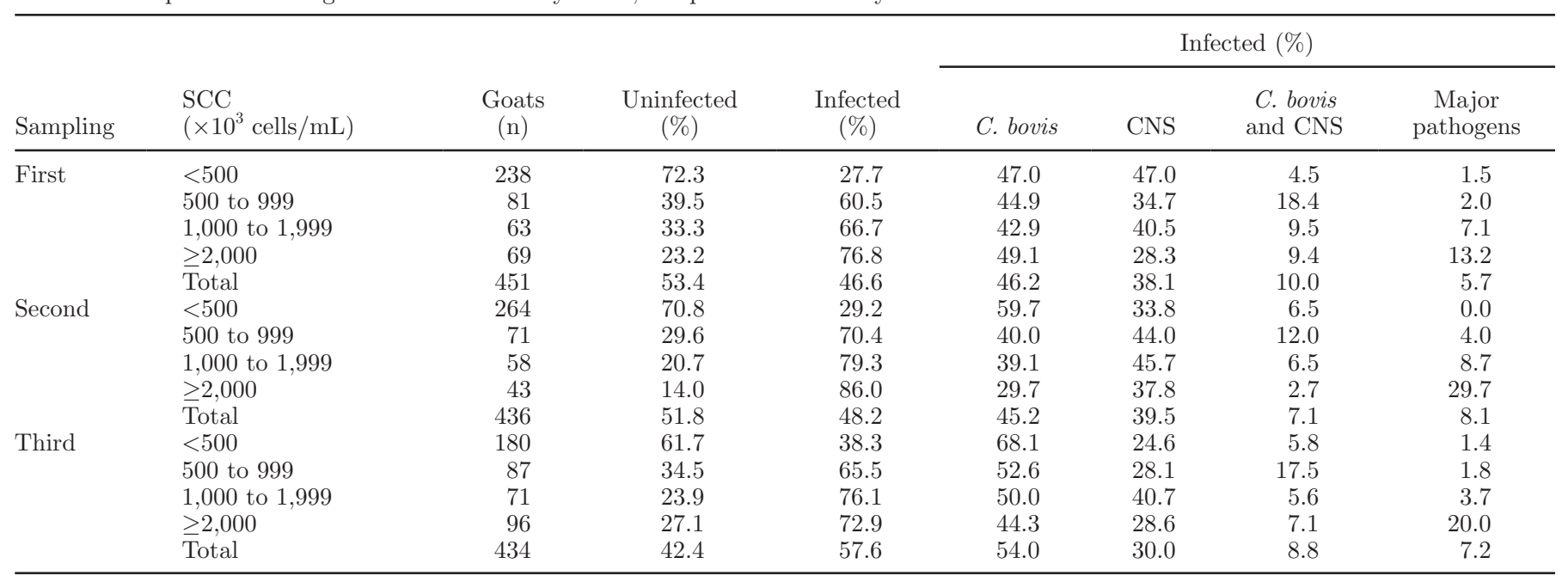


Table 3. Estimates of the effect on milk yield $(\mathrm{kg} / \mathrm{d})$ of infection with Corynebacterium bovis, CNS, a mixed infection with $C$. bovis and CNS, or infection with major pathogens in 2 linear mixed models with a random effect for goat within herd and fixed effects for parity, weeks in milk, and pregnancy ${ }^{1}$

\begin{tabular}{|c|c|c|c|c|}
\hline \multirow[b]{2}{*}{ Item } & \multicolumn{2}{|c|}{ Model 1} & \multicolumn{2}{|c|}{ Model 2} \\
\hline & $\beta$ & $\begin{array}{c}95 \% \text { CI } \\
(\beta)\end{array}$ & $\beta$ & $\begin{array}{c}95 \% \text { CI } \\
(\beta)\end{array}$ \\
\hline Uninfected & Reference class & & Reference class & \\
\hline C. bovis & 0.21 & 0.01 to 0.41 & 0.48 & 0.20 to 0.76 \\
\hline CNS & 0.04 & -0.14 to 0.22 & 0.10 & -0.11 to 0.32 \\
\hline C. bovis $+\mathrm{CNS}$ & 0.42 & 0.11 to 0.73 & 0.47 & 0.03 to 0.91 \\
\hline Major pathogens & -0.13 & -0.50 to 0.24 & -0.29 & -0.76 to 0.19 \\
\hline
\end{tabular}

${ }^{1}$ Model 1 used bacterial culture data from 3 occasions in lactation (1,321 records from 470 animals in 5 Dutch dairy herds); model 2 estimated the effect of infection status in the first month on the consecutive 42 wk of lactation (2,901 records from 446 animals in 5 herds).

association between infection with CNS and MY was recently described in heifers (Piepers et al., 2010) and in cows (Schukken et al., 2009). At least 2 explanations are possible for such findings: higher producing animals may be at greater risk of infection with minor pathogens, or infection with a minor pathogen somehow has a beneficial effect on milk production. Gröhn et al. (1995) showed that higher milk production in the previous lactation was associated with greater risk of clinical mastitis, with the possible explanation that higher producing cows were at greater risk of teat injury and of leaking milk between milkings, both of which are risk factors for clinical mastitis. In a more recent study, cows with clinical mastitis were shown to have a higher average MY before diagnosis than healthy cows (Gröhn et al., 2004). Although this was not the case for clinical mastitis caused by minor pathogens such as $C$. bovis, an increased risk of infection in higher yielding animals cannot be ruled out as a possible explanation. Beneficial effects of infection with a minor pathogen also have been described in cattle. Lam et al. (1997) showed that quarters with a natural infection with $C$. bovis were at lower risk of acquiring an infection with a major pathogen. The lower incidence of clinical mastitis or subclinical major infections may prevent milk losses and thereby be associated with higher average production. In our study, however, cases of clinical mastitis were excluded from the analyses. Furthermore, the prevalence of major infections was low. Therefore, a lower occurrence of (sub)clinical major IMI is probably not sufficient to explain such a large positive effect of infection with $C$. bovis. The fact that $C$. bovis infections were present in large numbers in only 2 of the 5 herds raises the question of whether the observed relationship was confounded by herd. We corrected for herd by including it in the model as a random effect, and running the models with a fixed herd effect yielded comparable estimates. One herd, however, had a very high prevalence of C. bovis (approximately $75 \%$ in early lactation and about $84 \%$ at the late lactation sampling). This may have resulted in unstable estimates for farm or C. bovis infection or both. Nevertheless, the animals in this herd had a lower MY than the average animal in this study, making too-high MY estimates for infection with $C$. bovis improbable. We also reran models 1 and 2 after exclusion of the high-prevalence herd to see the effect of this herd on the estimates. The estimates for C. bovis and for C. bovis + CNS increased somewhat after exclusion. The estimate for major pathogens in model 1 also increased slightly, but the other estimates remained approximately the same. This means that although this herd had an unusually high prevalence of C. bovis, this did not strongly affect the observed relationship between IMI and MY. A prevalence of $C$. bovis of approximately $36 \%$ in early lactation and about $67 \%$ in late lactation was observed in a second herd; in the other herds, the prevalence was below 3\% throughout the lactation, and in one herd, the pathogen was not found at all. This implies that the positive association between $C$. bovis culture and MY is actually based on 2 herds and cannot be readily generalized. More research is needed to confirm our findings and elucidate the biological mechanisms behind this effect.

\section{SCC and MY}

Table 4 shows the relationship between SCC class and MY in the full data set and in a subset of the data, with only the animals included that were culture negative at all 3 samplings. Remarkably, the effect of SCC class on MY is less pronounced in the full data set than in culture-negative animals. The often described negative relationship between SCC and MY (Zeng and Escobar, 1995; Zeng et al., 1997; Moroni et al., 2005a) seems thus to be attenuated by the presence of infected animals. Min et al. (2007) also described that in uninfected glands, SCC decreased as MY increased. It is often assumed that SCC can be used as a proxy for IMI 
Table 4. Estimate of the effect on milk yield $(\mathrm{kg} / \mathrm{d})$ of SCC class in 2 linear mixed models, corrected for weeks in milk, herd, parity, and pregnancy as fixed effects and a random goat effect ${ }^{1}$

\begin{tabular}{|c|c|c|c|c|}
\hline \multirow[b]{2}{*}{$\begin{array}{l}\text { SCC class } \\
\left(\times 10^{3} \text { cells } / \mathrm{mL}\right)\end{array}$} & \multicolumn{2}{|c|}{ Full data set } & \multicolumn{2}{|c|}{$3 \times$-culture-negative animals } \\
\hline & $\beta$ & $\begin{array}{c}95 \% \text { CI } \\
(\beta)\end{array}$ & $\beta$ & $\begin{array}{c}95 \% \text { CI } \\
(\beta)\end{array}$ \\
\hline$<500$ & Reference class & & Reference class & \\
\hline 500 to 999 & 0.02 & -0.07 to 0.12 & -0.24 & -0.45 to -0.03 \\
\hline 1,000 to 1,999 & -0.06 & -0.17 to 0.04 & -0.48 & -0.73 to -0.22 \\
\hline$\geq 2,000$ & -0.30 & -0.41 to -0.18 & -0.50 & -0.83 to -0.16 \\
\hline
\end{tabular}

${ }^{1}$ The first model was based on the full data set (3,075 records from 475 goats in 5 Dutch dairy herds); the second model only included animals that were culture-negative in both duplicate samples at all 3 sampling occasions (403 observations on 66 goats in 5 herds)

and that an increase in SCC "causes" a decrease in MY. This hypothesizes a negative association between IMI and MY and a positive association between IMI and SCC. We showed that IMI is indeed positively related to SCC, but that the negative relationship between IMI and $\mathrm{MY}$ is small for infection with major pathogens and that this relationship is even positive for infection with $C$. bovis. Therefore, the observed negative correlation between SCC and MY can be explained only to a limited extent by IMI. A possible causal diagram that explains the interrelationships between MY, IMI, and SCC and the effect of lactation stage and pregnancy is shown in Figure 1. We hypothesize that in dairy goats, a dilution effect explains most of the negative correlation between MY and SCC. Milk yield was significantly lower in the highest SCC class than in the lowest SCC class, which is illustrated by Figure 2. This figure also shows that SCC follows approximately the inverse lactation curve, and the peak production coincides with the lowest SCC, as was previously demonstrated by Rota et al. (1993), illustrating that MY and SCC are inversely correlated. Two important factors that affect MY are lactation stage and pregnancy (Zeng et al., 1997; Salama et al., 2005). Table 5 shows that the observed $\beta$ in a model that regresses $\log \mathrm{SCC}$ on MY was markedly reduced when lactation stage or pregnancy or both were included in the model. This means that MY and SCC are directly or indirectly related to lactation stage or pregnancy. It is difficult to discern the effect of pregnancy from the effect of lactation stage on MY, as these 2 variables are collinear. Our data set (part 2 ), however, provided an opportunity to study this because a substantial number of goats had an extended lactation ( $\geq 2 \mathrm{yr}$ ) and were therefore not pregnant at the stage that would normally be late lactation. We observed that, after correcting for lactation stage, inclusion of pregnancy added significantly to the model (data not shown), but it had a small additional effect on the association between MY and SCC (Table 5). The effect of pregnancy on MY was significant from the first month after conception in the part 2 data set (data not shown), which was earlier than in the study of Salama et al. (2005). The effect of pregnancy in our study may, however, be biased by the fact that in our observational study, farmers tended to breed the loweryielding animals and extend the lactations of higheryielding animals. The true effect of pregnancy may therefore be smaller than what we observed here. Apart from a dilution effect, there may also be a direct effect of lactation stage on SCC (Figure 1), which is caused by increased polymorphonuclear neutrophilic leukocyte chemotactic activity of nonmastitic late-lactation milk, as described by Manlongat et al. (1998). This is a nonpathological phenomenon in late-lactation goats and possibly plays a role in mammary gland involution. It is unclear, however, how important this mechanism is in explaining the high SCC in late lactation compared with what can be attributed to a concentration effect caused by a decreased MY.

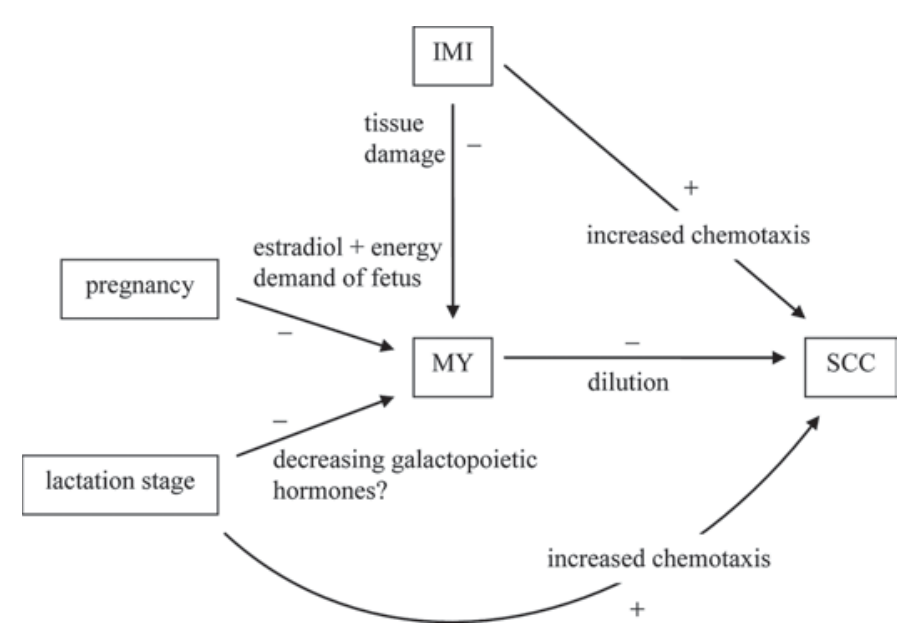

Figure 1. The hypothesized causal diagram of the relationship between milk yield (MY), IMI, and SCC and the effect of lactation stage and pregnancy. A positive relationship is indicated by + and a negative relationship by - 


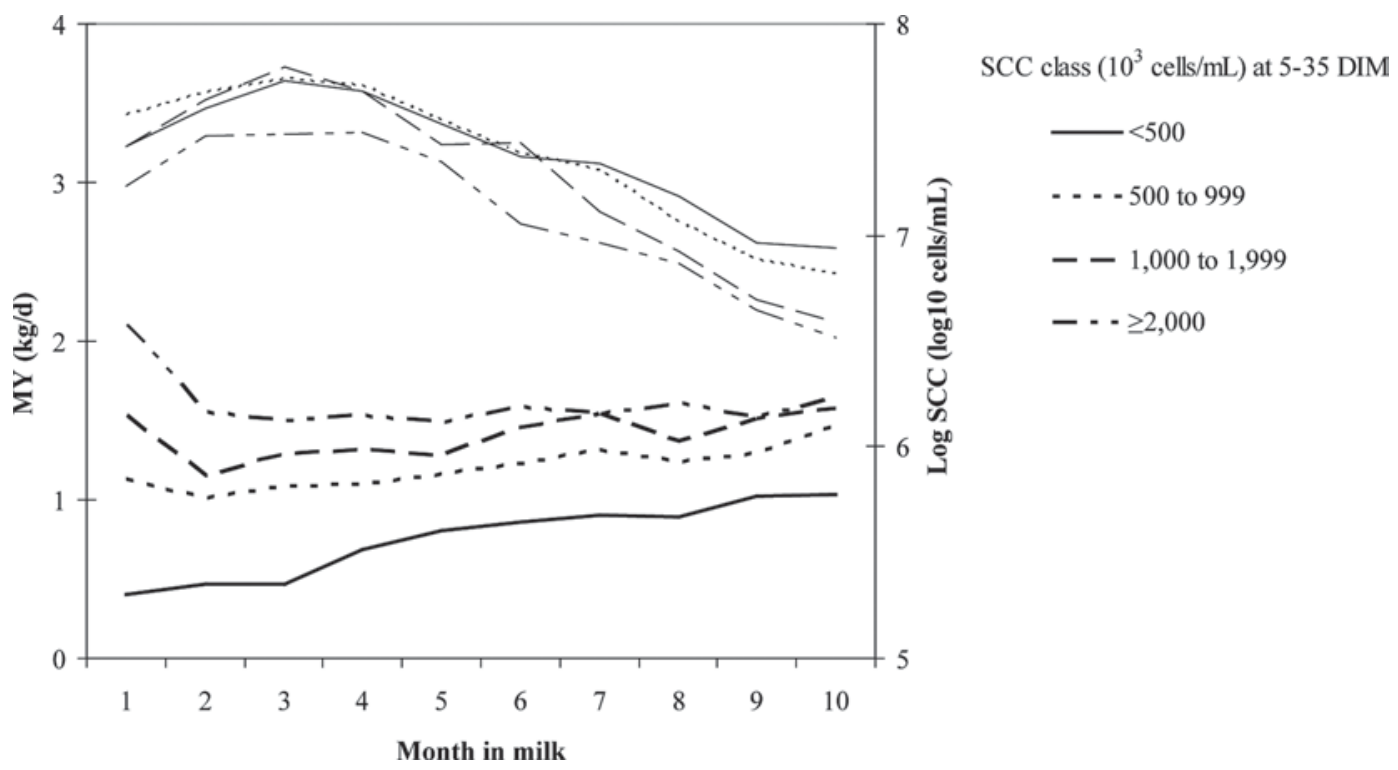

Figure 2. Observed mean daily milk yield (MY, thin lines) and $\log _{10}$-transformed SCC (logSCC, thick lines) for goats with a first SCC record (between 5 and 35 DIM) of $<500,500$ to $999,1,000$ to 1,999, and $\geq 2,000 \times 10^{3}$ cells $/ \mathrm{mL}$ based on 9,033 records from 1,685 goats in 6 Dutch dairy herds in the first 10 mo of lactation.

In conclusion, IMI is related to SCC, but is related only to a limited extent to MY, whereas SCC seems to be affected by dilution and increased chemotactic activity. Therefore, production losses due to subclinical mastitis in goats cannot be directly estimated from increased SCC, as is the case in cattle (Hortet and Seegers, 1998; Halasa et al., 2007).

\section{CONCLUSIONS}

Subclinical IMI significantly increased SCC. The effect of infection on MY was different for various pathogen groups. Infection with major pathogens was associated with a small decrease in MY; infection with CNS was not associated with a significant change in MY, and infection with $C$. bovis was associated with significantly higher MY. The latter finding remains to

Table 5. Estimate of the effect of $\log _{10}$-transformed SCC (logSCC) on milk yield, when corrected for weeks in milk, pregnancy, or a combination of these variables ${ }^{1}$

\begin{tabular}{lcc}
\hline Independent variable & $\beta$ & $95 \%$ CI \\
\hline logSCC & -0.53 & -0.55 to -0.51 \\
logSCC + lactation stage & -0.31 & -0.32 to -0.29 \\
logSCC + pregnancy & -0.38 & -0.40 to -0.36 \\
logSCC + lactation stage + pregnancy & -0.26 & -0.28 to -0.24 \\
\hline
\end{tabular}

${ }^{1}$ The models had random effects for lactation within goat within herd and are based on 25,837 records in 5,996 lactations of 4,493 goats in 6 Dutch dairy herds. be biologically explained. The correlation between SCC and MY was stronger in a subset of uninfected animals than in the total data set, and a dilution effect seems to play an important role in the negative association between SCC and MY. Therefore, SCC alone cannot be used to estimate production losses due to subclinical mastitis in goats.

\section{ACKNOWLEDGMENTS}

We gratefully acknowledge the farmers that participated in this study. We thank L. Clarijs and F. Koning (ELDA, Rijen, the Netherlands) for their help with the data collection. We thank the members of the feedback group: A. Bink and M. Paauw (Dutch Federation of Agriculture and Horticulture, the Hague, the Netherlands), L. Delhaes (Veterinary Surgeons Midden Brabant, Diessen, the Netherlands), H. Miltenburg (Animal Health Service, Deventer, the Netherlands), J. van Wegen and H. Voogd (Dutch Association for Quality Assurance in Goat Farming, Giessenburg, the Netherlands), and P. Witlox (Dutch Dairy Board, Zoetermeer, the Netherlands) for helpful discussions during set up and analyses of this study. C. Burvenich (Department of Comparative Physiology and Biometrics, Ghent University, Merelbeke, Belgium) is acknowledged for critical reading of the manuscript. This study was financially supported by the Dutch Dairy Board and the Dutch Association for Quality Assurance in Goat Farming (VKGN). 


\section{REFERENCES}

Baudry, C., R. de Cremoux, C. Chartier, and G. Perrin. 1997. Incidence de la concentration cellulaire du lait de chevre sur sa production et sa composition. Vet. Res. 28:277-286.

Caruolo, E. V. 1974. Milk yield, composition, and somatic cells as a function of time of day in goats under a continuous lighting regimen. Br. Vet. J. 130:380-387.

Contreras, A., J. C. Corrales, D. Sierra, and J. Marco. 1995. Prevalence and aetiology of non-clinical intramammary infection in MurcianoGranadina goats. Small Rumin. Res. 17:71-78.

Contreras, A., C. Luengo, A. Sánchez, and J. C. Corrales. 2003. The role of intramammary pathogens in dairy goats. Livest. Prod. Sci. $79: 273-283$.

Counter, D. E. 1981. Outbreak of bovine mastitis associated with Corynebacterium bovis. Vet. Rec. 108:560-561.

de los Campos, G., D. Gianola, P. Boettcher, and P. Moroni. 2006. A structural equation model for describing relationships between somatic cell score and milk yield in dairy goats. J. Anim. Sci. 84:2934-2941.

Dulin, A. M., M. J. Paape, W. D. Schultze, and B. T. Weinland. 1983. Effect of parity, stage of lactation, and intramammary infection on concentration of somatic cells and cytoplasmic particles in goat milk. J. Dairy Sci. 66:2426-2433.

East, N. E., E. F. Birnie, and T. B. Farver. 1987. Risk factors associated with mastitis in dairy goats. Am. J. Vet. Res. 48:776-779.

Gröhn, Y. T., S. W. Eicker, and J. A. Hertl. 1995. The association between previous 305-day milk yield and disease in New York state dairy cows. J. Dairy Sci. 78:1693-1702.

Gröhn, Y. T., D. J. Wilson, R. N. González, J. A. Hertl, H. Schulte, G. Bennett, and Y. H. Schukken. 2004. Effect of pathogen-specific clinical mastitis on milk yield in dairy cows. J. Dairy Sci. 87:3358-3374.

Haenlein, G. F. W. 2002. Relationship of somatic cell counts in goat milk to mastitis and productivity. Small Rumin. Res. 45:163178.

Halasa, T., K. Huijps, O. Østerås, and H. Hogeveen. 2007. Economic effects of bovine mastitis and mastitis management: A review. Vet. Q. 29:18-31.

Hortet, P., and H. Seegers. 1998. Calculated milk production losses associated with elevated somatic cell counts in dairy cows: Review and critical discussion. Vet. Res. 29:497-510.

Kolkman, I., S. De Vliegher, C. De Schauwer, G. Opsomer, and A. de Kruif. 2006. Dealing with a dairy herd with an elevated bulk milk somatic cell count. Vlaams Diergen. Tijds. 75:11-17.

Koop, G., M. Nielen, and T. van Werven. 2009. Bulk milk somatic cell counts are related to bulk milk total bacterial counts and several herd-level risk factors in dairy goats. J. Dairy Sci. 92:43554364 .

Lam, T. J. G. M., Y. H. Schukken, J. H. Van Vliet, F. J. Grommers, M. J. M. Tielen, and A. Brand. 1997. Effect of natural infection with minor pathogens on susceptibility to natural infection with major pathogens in the bovine mammary gland. Am. J. Vet. Res. $58: 17-22$

Leitner, G., U. Merin, A. Glickman, L. Weisblit, O. Krifucks, A. Shwimmer, and A. Saran. 2004a. Factors influencing milk quantity and quality in Assaf sheep and goat crossbreds. S. Afr. J. Anim. Sci. 34:162-164.

Leitner, G., U. Merin, and N. Silanikove. 2004b. Changes in milk composition as affected by subclinical mastitis in goats. J. Dairy Sci. $87: 1719-1726$.

Manlongat, N., T. J. Yang, L. S. Hinckley, R. B. Bendel, and H. M. Krider. 1998. Physiologic-chemoattractant-induced migration of polymorphonuclear leukocytes in milk. Clin. Diagn. Lab. Immunol. 5:375-381.

Merin, U., N. Silanikove, F. Shapiro, S. Bernstein, and G. Leitner. 2004. Changes in milk composition as affected by subclinical mastitis in sheep and goats. S. Afr. J. Anim. Sci. 34:188-191.

Min, B. R., G. Tomita, and S. P. Hart. 2007. Effect of subclinical intramammary infection on somatic cell counts and chemical composition of goats' milk. J. Dairy Res. 74:204-210.

Moroni, P., G. Pisoni, M. Antonini, G. Ruffo, S. Carli, G. Varisco, and P. Boettcher. 2005a. Subclinical mastitis and antimicrobial susceptibility of Staphylococcus caprae and Staphylococcus epidermidis isolated from two Italian goat herds. J. Dairy Sci. 88:1694-1704.

Moroni, P., G. Pisoni, G. Ruffo, and P. Boettcher. 2005b. Risk factors for intramammary infections and relationship with somatic-cell counts in Italian dairy goats. Prev. Vet. Med. 69:163-173.

Moroni, P., G. Pisoni, C. Vimercati, M. Rinaldi, B. Castiglioni, P. Cremonesi, and P. Boettcher. 2005c. Characterization of Staphylococcus aureus isolated from chronically infected dairy goats. J. Dairy Sci. 88:3500-3509.

Piepers, S., G. Opsomer, H. W. Barkema, A. De Kruif, and S. De Vliegher. 2010. Heifers infected with coagulase-negative staphylococci in early lactation have fewer cases of clinical mastitis and higher milk production in their first lactation than noninfected heifers. J. Dairy Sci. 93:2014-2024.

Pinheiro, J., D. Bates, S. DebRoy, D. Sarkar, and the R core team. 2009. NLME: Linear and nonlinear mixed effects models; $\mathrm{R}$ package version 3. http://www.r-project.org/.

Reksen, O., L. Sølverød, and O. Østerås. 2007. Relationships between milk culture results and milk yield in Norwegian dairy cattle. J. Dairy Sci. 90:4670-4678.

Rota, A. M., C. Gonzalo, P. L. Rodriguez, A. I. Rojas, L. Martin, and J. J. Tovar. 1993. Effects of stage of lactation and parity on somatic cell counts in milk of Verata goats and algebraic models of their lactation curves. Small Rumin. Res. 12:211-219.

Salama, A. A. K., G. Caja, X. Such, R. Casals, and E. Albanell. 2005. Effect of pregnancy and extended lactation on milk production in dairy goats milked once daily. J. Dairy Sci. 88:3894-3904.

Sánchez, A., A. Contreras, and J. C. Corrales. 1999. Parity as a risk factor for caprine subclinical intramammary infection. Small Rumin. Res. 31:197-201.

Sánchez, A., C. Fernandez, A. Contreras, C. Luengo, and J. Rubert. 2002. Effect of intramammary infection by Staphylococcus caprae on somatic cell counts and milk composition in goats. J. Dairy Res. 69:325-328.

Schuiling, H. J. 2007. Prolonged lactations in goats. Report 97. Animal Sciences Group, Wageningen, the Netherlands.

Schukken, Y. H., R. N. González, L. L. Tikofsky, H. F. Schulte, C. G. Santisteban, F. L. Welcome, G. J. Bennett, M. J. Zurakowski, and R. N. Zadoks. 2009. CNS mastitis: Nothing to worry about? Vet. Microbiol. 134:9-14.

Smith, M. C., and D. M. Sherman. 2009. Reproductive system. Pages 571-645 in Goat Medicine. 2nd ed. Wiley-Blackwell, Ames, IA.

Van den Brom, R., and P. Vellema. 2009. Q fever outbreaks in small ruminants and people in the Netherlands. Small Rumin. Res. $86: 74-79$

Zeng, S. S., and E. N. Escobar. 1995. Effect of parity and milk production on somatic cell count, standard plate count and composition of goat milk. Small Rumin. Res. 17:269-274.

Zeng, S. S., E. N. Escobar, and T. Popham. 1997. Daily variations in somatic cell count, composition, and production of Alpine goat milk. Small Rumin. Res. 26:253-260. 